ARTIGO ORIGINAL

\title{
Ansiedade pré-competitiva e desempenho em jovens atletas de ginástica rítmica: um estudo de caso
}

\author{
Precompetitive anxiety and performance in young rhythmic gymnastics athletes: a case study
}

Camila Mendes Marques, Shauane Emanuela Fornaciari Silva, Veronica Volski Mattes, Ana Carolina Paludo Universidade do Centro Oeste do Paraná (Unicentro), Guarapuava/PR, Brasil

HISTÓRICO DO ARTIGO

Recebido: 25 outubro 2019

Revisado: 09 setembro 2020

Aprovado: 23 setembro 2020

\section{PALAVRAS-CHAVE:}

Ginástica rítmica; Competição; Desempenho.

\section{KEYWORDS:}

Rhythmic Gymnastic; Competition; Performance.

\section{RESUMO}

INTRODUÇÃO: A ginástica rítmica é caracterizada pela participação precoce das atletas em treinamento e competição. Essa participação pode causar altos níveis de ansiedade, podendo impactar negativamente no desempenho esportivo.

OBJETIVO: Verificar as respostas de ansiedade pré-competitiva e de desempenho em atletas da ginástica rítmica.

MÉTODOS: Foram avaliadas 2 atletas de ginástica rítmica, com idade de 11 e 12 anos, nos aparelhos individuais de maças e corda, durante uma competição simulada e uma competição oficial. A ansiedade pré-competitiva foi avaliada pelo questionário CSAI-2R e o desempenho foi avaliado pela percepção da atleta e o score da arbitragem para cada apresentação.

RESULTADOS: Os dados descritivos sugerem que na competição oficial, as atletas apresentaram maiores valores de ansiedade somática e cognitiva; seguido de uma maior percepção de desempenho. Para a pontuação da arbitragem, as atletas apresentaram maiores valores para o aparelho maças e menores valores no aparelho corda na competição oficial quando comparado a competição simulada.

CONCLUSÃO: Os resultados do presente estudo sugerem que, a ansiedade pré-competitiva tende a ser maior em situações mais estressantes (competição oficial vs. simulada), porém esse comportamento parece não influenciar negativamente o desempenho das ginastas nas apresentações individuais.

\section{ABSTRACT}

BACKGROUND: Rhythmic gymnastics is characterized by an athlete's early participation in training and competition. This participation can cause high levels of anxiety and may impact negatively on sports performance.

OBJECTIVE: To verify the precompetitive anxiety and performance responses in rhythmic gymnastics athletes. METHODS: Two rhythmic gymnastics athletes, aged 11 and 12 years old, were evaluated in individual clubs and rope apparatus, during a simulated and official competition. Precompetitive anxiety was assessed by CSAI-2R questionnaire, and performance was assessed by the athlete's perception and jury score for each presentation. RESULTS: The descriptive data suggest that in the official competition, the athletes presented higher values of somatic and cognitive anxiety, followed by a greater perception of performance. For the jury score, the athletes presented higher values in clubs and lower values in the rope apparatus during the official competition than the simulated competition.

CONCLUSION: The results of the present study suggest that precompetitive anxiety tends to be higher in more stressful conditions (official vs. simulated competition), but this behavior does not seem to influence the performance of gymnasts in individual presentations negatively. 


\section{INTRODUÇÃO}

A Ginástica Rítmica (GR) é uma modalidade esportiva que relaciona de forma fluente o corpo, a música e o aparelho. Possui um lado artístico e outro desportivo, nos quais a expressão e os elementos corporais formam uma unidade entre atleta e o aparelho, exigindo a execução perfeita em sincronia e harmonia com a música (CORTZ; LOURENÇO, 2019). A GR também apresenta como característica principal a iniciação e especialização precoce das suas participantes.

A especialização esportiva precoce apresenta como objetivo principal a introdução da criança em um treinamento esportivo planejado e organizado a longo prazo, com foco no aumento gradual do desempenho, além da participação periódica em competições esportivas. Destaca-se que durante este período, a jovem atleta se encontra em processo de desenvolvimento e sua participação em competições oficiais pode ser encarada como uma situação estressante por diversos fatores como: pressão dos técnicos e familiares, presença de público, local da competição (KUNZ, 1994).

Devido a esse fator, torna-se indispensável que as possíveis respostas estressantes dessas jovens atletas, geradas pela competição esportiva, sejam acompanhadas constantemente; uma vez que essas atletas encontram-se na fase de desenvolvimento global e podem sofrer maior influência da pressão da competição, principalmente as ginastas que competem na categoria individual (KUNZ, 1994).

Atualmente, as respostas psicológicas dos atletas vem sendo amplamente investigadas e reportadas pela literatura científica, principalmente no que diz respeito a ansiedade pré-competitiva, que pode ser entendida como uma "reação emocional que consiste em uma única combinação de sentimentos de tensão, apreensão e nervosismo, bem como pensamentos desagradáveis (preocupação) e mudanças fisiológicas associada com a ativação do sistema nervoso autônomo" (SPIELBERGER, 1989).

Essas respostas de ansiedade pré-competitiva tendem a ser mais sensíveis em atletas de modalidades individuais quando comparados à atletas de modalidades coletivas (PLUHAR et al., 2019). Ademais, a ansiedade pré-competitiva tem sido analisada em conjunto com o desempenho esportivo, afim de melhor entender o seu possível efeito no desempenho do atleta (PALUDO et al., 2017). Quando se trata da GR, encontramos o estudo de Cottyn e colaboradores (2006), que avaliaram a ansiedade pré-competitiva e o desempenho esportivo de ginastas em competição indivi-dual e como principais resultados os autores não encontraram uma relação significativa dos níveis de ansiedade com o desem-penho das ginastas durante a competição.

Apesar do estudo de Cotty et al. (2006) não apresentar uma relação entre ansiedade e desempenho esportivo de ginastas, nota-se que essa temática ainda é pouco explorada pela literatura científica, principalmente em atletas de ginástica rítmica no nosso país. Sendo assim o objetivo primário do presente estudo foi verificar as respostas de ansiedade pré-competitiva e de desempenho esportivo em duas atletas da ginástica rítmica. Como objetivo secundário, o estudo procurou descrever as respostas de ansiedade pré-competitiva e desempenho nas condições de competição simulada e competição oficial.

\section{MÉTODOS}

Foram avaliadas 2 atletas de ginástica rítmica, do sexo feminino, com idade de 11 e 12 anos, pertencentes a uma equipe escolar da cidade de Guarapuava, Paraná, selecionadas de maneira intencional. Os critérios de inclusão do estudo foram: o interesse em participar do estudo, pertencer à faixa etária estabelecida, ser praticante da modalidade de GR, estar participando regularmente a pelo menos seis meses dos treinamentos e competição e a assinatura do Termo de Consentimento Livre Esclarecido pelos pais e/ou responsáveis e do Termo de Assentimento pela participante. Como critério de exclusão foi considerado a não participação da competição simulada e/ou competição oficial.

A primeira fase do estudo foi constituída pela entrega da proposta para a equipe de GR e para o colégio selecionado, seguida pela aprovação do estudo no Comitê de Ética em Pesquisa da Universidade Estadual do Centro-Oeste (Unicentro). Após a apresenta-ção da proposta, as atletas e seus responsáveis assinaram o Termo de Assentimento e Termo de Consentimento Livre e Esclare-cido (TCLE) respectivamente. O projeto foi aprovado pelo comitê de ética sobre o Parecer $n^{\circ}$ 3.130.343.

A coleta de dados foi realizada em três etapas: na primeira etapa foi feita a familiarização com o questionário CSAI-2R e a es-cala de percepção subjetiva de desempenho. Na segunda etapa foi realizada uma competição simulada com público externo; e por fim na terceira etapa foi realizada a coleta em competição oficial. Antes da competição simulada e oficial a ansiedade pré-competitiva foi avaliada pelo questionário CSAI-2R e após a competição foram registrados o desempenho percebido e o es-core da apresentação. A competição simulada foi filmada através de câmera posicionada em um local que pudesse abranger toda a área onde ocorreu a apresentação, para posterior análise da a pontuação final (Figura 1).

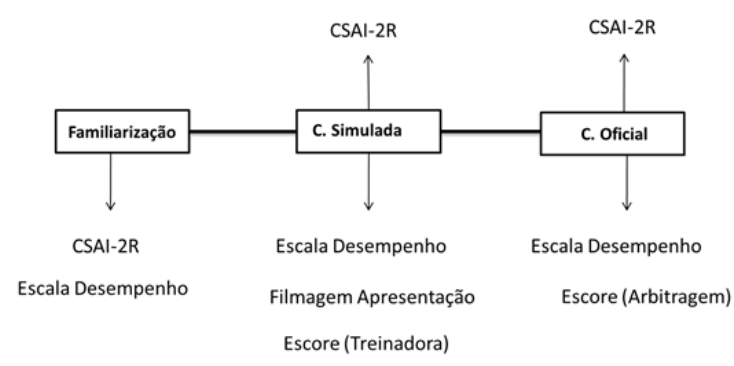

Figura 1. Desenho do estudo.

A ansiedade pré-competitiva foi avaliada pelo questionário Revised Competitive State Anxiety Inventory - 2 (CSAI-2R), uma adaptação realizada por Cox e colaboradores (2003) da versão original proposta por Martens e colaboradores (1990) do Competitive State Anxiety Inventory - 2 (CSAI-2). O CSAI-2R é composto por 17 questões distribuídas em três domínios: cognitivo, somá-tico e autoconfiança. Cada questão tem a opção de quatro alternativas de resposta mediante a Escala Likert de 1 a 4 (1=nada a $4=$ muito). A versão em Português do questionário apresenta valores aceitáveis para as propriedades psicométricas, sustentando a sua utilização em atletas brasileiros, segundo o trabalho realizado por Fernandes e colaboradores (2012). 
O desempenho foi avaliado de maneira subjetiva através de uma escala Likert de 1 (longe da melhor performance) à 5 (perto da melhor performance). A escala foi preenchida pelas atletas após a apresentação através da seguinte pergunta: "Qual foi o seu desempenho nessa apresentação". Adicionalmente, foram registrados o escore total da apresentação considerando o código de pontuação da "Fédération Internationale de Gymnastique (FIG)", sendo a somatória dos elementos de dificuldade e elementos execução. Para a competição simulada, a apresentação de cada atleta foi filmada e posteriormente analisada, e para a competição oficial registrou-se o escore final atribuído pela arbitragem.

Pelo número reduzido de participantes, optou-se pela não realização de testes estatísticos inferenciais, uma vez que aumentaria a chance de as análises serem enviesadas e acometidas pelo erro do tipo II (erro relacionado ao tamanho da amostra). Dessa maneira, a estatística descritiva foi utilizada para as respostas de ansiedade pré-competitiva e as demais variáveis, nas duas condições: competição simulada e competição oficial.

\section{RESULTADOS}

As respostas de ansiedade pré-competitiva (ansiedade somática e cognitiva; e autoconfiança) na competição simulada e oficial das duas atletas avaliadas estão apresentados na Figura 2.

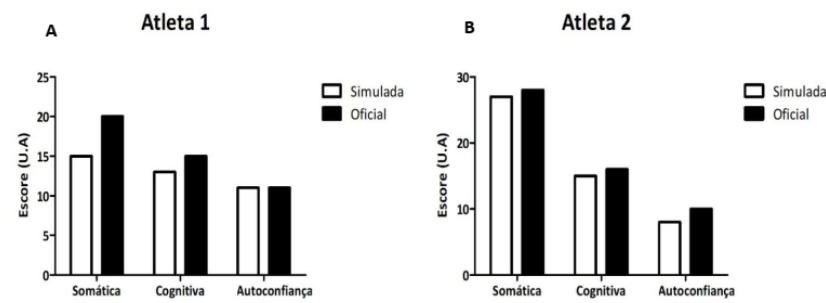

Figura 2. Ansiedade pré-competitiva na situação de competição simulada e oficial para atleta 1 (Figura 2A) e atleta 2 (Figura 2B).

As respostas de desempenho subjetivo para as atletas estão apresentadas na Figura 3 e os escores de pontuação de cada apresentação (maças e corda) estão apresentados na Figura 4.

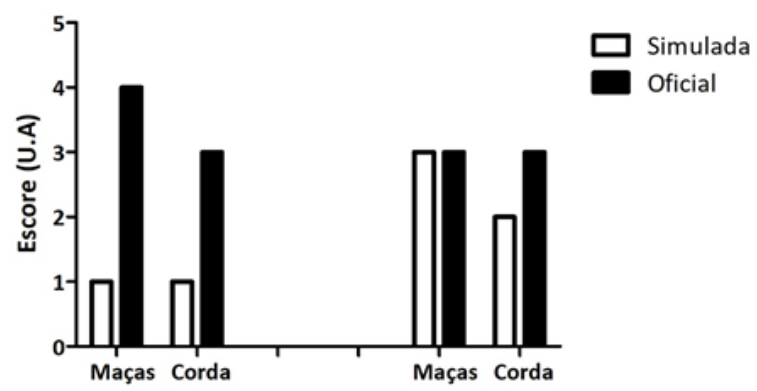

Atleta 1

Atleta 2

Figura 3. Desempenho Subjetivo na apresentação de maças e corda na competição simulada e oficial para as atletas 1 e 2 .

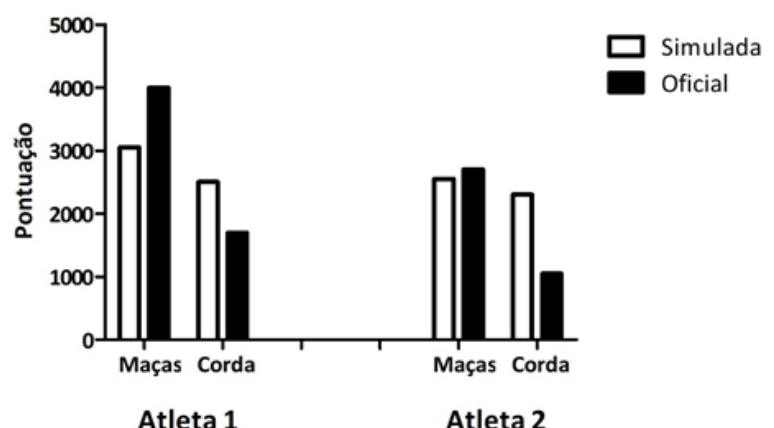

Figura 4. Desempenho pela pontuação na apresentação de maças e corda na competição simulada e oficial para as atletas 1 e 2 .

O presente estudo teve como objetivo principal analisar as respostas de ansiedade pré-competitiva e desempenho esportivo em duas atletas de GR, considerando as condições em competição simulada e competição oficial. Como principais resultados destacam-se: i) as respostas de ansiedade somática e cognitiva apresentaram maiores valores na competição oficial quando comparado à competição simulada (principalmente para a atleta 1); ii) as atletas perceberam um maior desempenho na competição oficial quando comparada a competição simulada; iii) a ansiedade pré-competitiva parece não influenciar negativamente na percepção de desempenho das atletas, durante a competição oficial.

A literatura científica tem demonstrado que a ansiedade pré-competitiva pode apresentar variações de acordo com o cenário contextual, como por exemplo o nível da competição (RÉ; BÖHME, 2004). Entende-se que competições com maior notoriedade pode levar o atleta a apresentar maiores pensamentos de preocupação e tensão e maior excitação fisiológica. Estudos com jovens atletas de modalidades individuais confirmam o pressuposto contextual nas respostas de ansiedade, como no caso do judô, na qual os jovens atletas demonstraram maiores valores de ansiedade cognitiva durante a fase inter-regional quando comparado a fase regional (FILAIRE et al., 2001). Em jovens atletas de natação, uma maior ansiedade pré-competitiva foi encontrara durante a competição regional quando comparado a competição estadual (BARBACENA; GRISI, 2008).

No presente estudo, as respostas de ansiedade pré-competitiva das atletas corroboraram com as repostas reportadas pelos estudos acima. Observou-se que, principalmente para a atleta 1 , as respostas de ansiedade somática e cognitiva apresentaram maiores valores na competição oficial quando comparado a competição simulada. Para a atleta 2 essa variação nos valores de ansiedade foi menor, porém percebe-se que esta atleta apresentou maiores valor de ansiedade somática e menores valores de autoconfiança nas duas situações (simulada e oficial) quando comparada a atleta 1 .

Ao analisarmos a relação entre ansiedade e desempenho, parece que as maiores repostas de ansiedade durante a competição oficial não afetaram negativamente a percepção de desempenho e escore (nota) da apresentação. A atleta 1 apresentou resposta de desempenho percebido expressivamente maior na competição oficial para ambos aparelhos, assim como o escore da apresentação do aparelho maças. Entretanto para atleta 2, o desempenho percebido foi maior para o aparelho corda, porém maior escore da apresentação no aparelho maças. Ambas as atletas apresentarem um escore de apresentação do aparelho corda menor na condição de competição oficial (vs. si- 
mulada). Uma possível explicação para um menor desempenho nesse aparelho, segundo reportado pela equipe técnica, foi que a prioridade no treinamento das atletas destinou-se ao apareIho maças.

A relação entre ansiedade e desempenho ainda apresenta resultados inconclusivos, ou seja, ainda não é consenso na literatura se a ansiedade pré-competitiva pode afetar negativamente o desempenho esportivo (PALUDO et al., 2016). Uma das possíveis justificativa para as diferentes respostas de ansiedade e desempenho se dá pelo fato das diferentes metodologias aplicadas principalmente para avaliação do desempenho. No presente estudo o desempenho foi avaliado tanto pela percepção subjetiva quanto pelo escore da apresentação, sendo que ambos os valores não foram afetados negativamente com o aumento da ansiedade pré-competitiva. De maneira similar, o estudo de Cottyn et al. (2006), avaliaram a ansiedade pré-competitiva e o desempenho através do escore da apresentação de ginastas na trave de equilíbrio, e como principais resultados os autores destacaram que as dimensões do questionário CSAI-2 (ansiedade somática, cognitiva e autoconfiança) não apresentaram um relacionamento significativo com o desempenho das ginastas durante uma competição.

Apesar do presente estudo ser um dos primeiros a descrever as respostas de ansiedade pré-competitiva e desempenho esportivo em atletas GR, vale a pena destacar as suas limitações. O número reduzido de atletas avaliadas torna-se a principal limitação, pois com uma amostra reduzida não foi possível utilizar análise estatística inferencial para poder testar um possível relacionamento entre ansiedade e desempenho considerando a fase da competição. A análise descritiva vem sendo utilizada em estudos com número reduzidos de participantes, por fornecer respostas importantes a serem consideradas e discutidas. Recentemente Souza et al. (2019) também optaram pela análise descritiva ao relatar os comportamentos de ansiedade pré-competitiva em 4 jovens atletas de judô durante o campeonato brasileiro de judô.

Outra limitação a se considerar foi a avaliação da ansiedade no início da competição oficial e não minutos antes da apresentação de cada aparelho; uma avaliação da ansiedade principalmente antes do aparelho corda poderia explicar um menor escore na apresentação durante competição oficial. Adicionalmente, a avaliação apenas de duas atletas em dois aparelhos individuais limitando assim a extrapolação dos dados a atletas com características diferentes da amostra analisada.

\section{CONCLUSÃO}

De acordo com os resultados apresentados pelo presente estudo, podemos observar que a ansiedade pré-competitiva de jovens atletas de ginástica rítmica pode variar conforme o nível da competição, na qual maiores valores de ansiedade somática e cognitiva foram apresentados na condição de competição oficial quando comparado a competição simulada. Entretanto, essa variação nos valores de ansiedade parece não ter influenciado negativamente no desempenho percebido das atletas durante as apresentações, uma vez que maiores valores de desempenho foram reportados durante a competição oficial. Dessa maneira, podemos concluir que a ansiedade pré-competitiva tende a ser maior em situações mais estressantes (ex: competição oficial), porém esse comportamento parece não influenciar negativamente sobre o desempenho percebido e escore final de atletas de ginástica rítmica em apresentações individuais.

\section{REFERÊNCIAS}

BARBACENA, M. M.; GRISI, R. N. F. Nível de ansiedade pré-competitiva em atletas de natação. Conexões, Campinas, v. 6, n. 1, p. 31-38, 2008.

COTTYN, J.; DE CLERCQ, D.; PANNIER, J. L.; CROMBEZ, G.; LENOIR, M. The measurement of competitive anxiety during balance beam performance in gymnasts. Journal of Sports Science, London, v. 24, p. 57-164, 2006.

CORTZ, R. V.; LOURENÇO, M. R. A. Exercícios compensatórios na ginástica rítmica: possibilidades de reduções de lesões. Várzea Paulista: Fontoura, 2019

COX, R. H.; MARTENS, M. P.; RUSSELL, W. D. Measuring anxiety in athletics: the revised competitive state anxiety inventory-2. Journal of Sport \& Exercise Psychology, Champaign, n. 25, p. 519-33, 2003.

FILAIRE, E.; SAGNOL, M.; FERRAND, C.; MASO, F.; LAC, G. Psychophysiological stress in judo athletes during competitions. Journal of Sports Medicine Physical Fitness, Rome, v. 41, p. 263-8, 2001.

KUNZ, E. As dimensões inumanas do esporte de rendimento. Movimento, Porto Alegre, v. 1, n. 1, p. 23-28, 1994.

MARTENS, R.; VEALEI, R. S.; BURTON, D. Competitive anxiety in sport. Champaign: Human Kinetics, 1990.

PALUDO, A. C.; NUNES, A. S; SIMÕES, A. C; GIMENES, M. Relação entre ansiedade competitiva, autoconfiança e desempenho esportivo: uma revisão ampla da literatura. Psicologia \& Argumento, Curitiba, v. 34, p. 156-69, 2016.

PLUHAR, E.; MCCRACKEN, C.; GRIFFITH, K. L.; CHRISTINO, M. A.; SUGIMOTO, D.; MEEHAN W. P. Team sport athletes may be less likely to suffer anxiety or depression than individual sport athletes. Journal of Sports Science \& Medicine, Bursa, v. 18, p. 490-6, 2019.

RÉ, A. H. N.; DE ROSE JR., D.; BÖHME, M. T. S. Stress e nível competitivo: considerações sobre jovens praticantes de futsal. Revista Brasileira de Ciência e Movimento, Brasília, v. 12, n. 4, p. 83-7, 2004.

SPIELBERGER, C. D. State-trait anxiety inventory: a comprehensive biblografy. Palo Alto: Consulting Psychologists Press, 1989.

SOUZA, J. P.; LOBO, C. C.; DOS ANJOS, C. L.; PASSARELI, L. F. M. Ansiedade pré-competitiva em atletas das categorias de base: relato de experiência em campeonato brasileiro de judô. Caderno de Educação Física e Esporte, Marechal Cândido Rondon, v. 17, n. 2, p. 77-81, 2019.

\section{AGRADECIMENTOS}

Os autores agradecem ao Departamento de Educação Física da Universidade do Centro-Oeste do Paraná (Unicentro) pelo apoio na execução do projeto e as atletas envol-vidas na pesquisa.

\section{CONFLITO DE INTERESSE}

Os autores do estudo declaram não haver conflito de interesses

\section{FINANCIAMENTO}

Este estudo não teve nenhum apoio financeiro.

\section{ORCID E E-MAIL DOS AUTORES}

Camila Mendes Marques

ORCID: 0000-0002-6540-1599.

E-mail: mila_.m.m@hotmail.com

Shauane Emanuela Fornaciari Silva ORCID: 0000-0002-5738-0644.

E-mail: shauanemanuela@gmail.com

Veronica Volski Mattes

ORCID: 0000-0002-9599-6618.

E-mail: vero_edf@hotmail.com

Ana Carolina Paludo (Autora Correspondente)

ORCID: 0000-0001-8771-4580.

E-mail: anacpaludo@gmail.com 